\title{
Simulation of seven years of field performance monitoring at Rio Tinto Iron Ore, Mount Tom Price Mine using soil-plant- atmosphere numerical modelling
}

\author{
R.E. Shurniak O'Kane Consultants Inc., Canada \\ M.A. O'Kane O'Kane Consultants Inc., Canada
}

R. Green Rio Tinto Iron Ore, Australia

\begin{abstract}
Cover systems that utilise the moisture store-and-release (S\&R) concept rely on the ability of the cover material to possess sufficient moisture retention capabilities. Infiltrating waters are then 'stored' within the cover material, and subsequently 'released' to the atmosphere as evapotranspiration. As a result, net percolation (recharge) to the underlying waste is minimised. A key aspect of achieving low net percolation rates is the ability of the cover material to manage high infiltration rates (resulting from intense and long duration rainfall events) through development of a vegetative cover that can utilise (transpire) moisture that has migrated deep into the cover profile.
\end{abstract}

Rio Tinto Iron Ore's (RTIO) Mount Tom Price open-cut iron ore mining operation located in the semi-arid Pilbara region of Western Australia has waste rock dumps that are partially comprised of material considered to be net acid generating. Hence, suitable cover options for the waste rock dumps were investigated and preliminary cover system designs that utilise the $S \& R$ concept were recommended for further investigation. To this end, two cover system field trials, TP1 and TP2, were constructed in July 2003, consisting of a $4 \mathrm{~m}$ thick coarser textured run-of-mine (ROM) material and a $2 \mathrm{~m}$ finer textured ROM material, respectively. Measurements of soil temperature, suction, and water content within the cover trials have been collected continuously since their construction. As a result, a unique set of cover system monitoring data has developed over a seven year period; this includes performance monitoring of the trial covers for bare-surface conditions, followed by a period of vegetation establishment, which is now substantially influencing cover system performance.

Numerical modelling was undertaken to simulate field responses measured at the two field trials to develop a set of calibrated model inputs, which could then be used to develop a better understanding of long-term cover system performance. Simulating the measured field responses is a challenging process because of the numerous variables influencing soil-plant-atmosphere flow regimes. Despite these difficulties, the calibrated models were able to acceptably simulate field responses, with TP1 and TP2 having coefficient of determination values of 0.86 and 0.92 , respectively, over the period. These calibrated model inputs were then used to estimate how the cover systems would perform over a 100 year period. The 100 year simulations estimate that both cover systems limit net percolation to less than $5 \%$ of average annual rainfall.

\section{Introduction}

Rio Tinto Iron Ore's (RTIO) Mount Tom Price mine is located approximately 1,000 km north-northeast of Perth and $370 \mathrm{~km}$ south-southeast of Karratha in the semi-arid Pilbara region of Western Australia. Its open-cut iron ore mining operations were initiated in 1966 with a yearly production capacity of 28 million tonnes (RTIO, 2012). Material within some waste rock dumps produced from the operations is considered to be net acid generating. Hence, preliminary closure planning for the mine site required that research of suitable cover options for the waste rock dump be completed. 
The two principal design objectives of cover systems for potentially net acid generating waste are (MEND, 2004):

1. To function as a water infiltration barrier for the underlying waste material as a result of the presence of a low permeability layer and/or a moisture store-and-release (S\&R) layer.

2. To function as an oxygen ingress barrier for the underlying waste material by maintaining a high degree of saturation within a layer of the cover, thereby minimising the effective oxygen diffusion coefficient and ultimately controlling the flow of oxygen across the cover.

As a result of the high evaporative conditions at the site, preliminary cover system designs focused primarily on limiting infiltration of meteoric water by utilising the S\&R concept to its full potential. Cover systems that utilise the $S \& R$ concept rely on the ability of the cover material to possess sufficient moisture retention such that infiltrating waters are 'stored' within the cover layer, and subsequently 'released' to the atmosphere as evapotranspiration such that net percolation (recharge) to the underlying waste is minimised. A key aspect of achieving low net percolation rates is the ability of the cover material to manage high infiltration rates (resulting from intense and long duration rainfall events) through development of a vegetative cover that can utilise (transpire) moisture that has migrated deep into the cover profile.

Two S\&R cover system field trials were constructed on-site to aid engineering judgement with regards to the optimum cover system design for mine closure planning and determine the anticipated water balance from such a design. Soil-plant-atmosphere numerical models, calibrated to simulate measured field responses from the trials (referred to hereinafter as a field response models), were completed to analyse performance of the trial cover systems over the monitoring period and develop a set of calibrated model inputs. The calibrated model inputs from field response models were then used in long-term performance models to evaluate performance for a variety of scenarios to aid in finalising a cover system design.

This paper describes the field trials, provides a summary of the calibration for the field response models, and provides estimates of long-term performance of the trial cover systems based on the calibrated models.

The computer software VADOSE/W 2007 (Geo-Slope International, 2009) was used to complete the modelling presented in this paper. VADOSE/W is a 2D finite element model (which can also perform 1D simulations) that predicts pressure head (suction) and temperature profiles in the soil profile in response to climatic forcing (such as evaporation) and lower boundary conditions (such as a water table). A key feature of VADOSE/W is the ability of the model to predict actual evaporation and transpiration based on potential evaporation and predicted soil suction, as opposed to the user being required to input these surface flux boundary conditions. The actual evapotranspiration rate is generally well below the potential rate during prolonged dry periods because the suction, or negative water pressure, in the soil profile increases as the surface desiccates. In addition, VADOSE/W is a fully coupled (through the vapour pressure term) heat and mass transfer model which is capable of predicting water vapour movement (Geo-Slope International, 2010).

\section{Description of field trials}

Two S\&R cover system field trials were constructed on-site in July 2003 consisting of a $4 \mathrm{~m}$ thick bandediron formation (coarser textured) run-of-mine (ROM) field trial (TP1) and a $2 \mathrm{~m}$ thick McRae Shale (finer textured) ROM field trial (TP2). Properties for each material are summarised in Table 1. The cover materials were paddock dumped using a haul truck and levelled to the required grade using a dozer. No compaction or moisture conditioning of the cover system field trials was required or specified; however, each cover system received nominal compaction due to the operation of construction equipment on the cover surface.

The two cover system field trials are immediately adjacent to each other and are designed to accept as much rainfall as possible, while minimising runoff and associated erosion, with all infiltration remaining within the extents of the cover trials. In situ moisture conditions at each field trial are automatically measured by Sentek EnviroSCAN ${ }^{\circledR}$ capacitance water content sensors (indirect measurement of volumetric 
water content) and thermal conductivity (TC) sensors (indirect measurement of matric suction). One sensor nest was installed at TP1 through to a depth of $400 \mathrm{~cm}$ within the cover material while at TP2 one sensor nest was installed throughout the depth of the cover material and into the underlying waste rock to a combined depth of $290 \mathrm{~cm}$. Each sensor nest location consists of 32 water content sensors and 32 TC sensors. Fully operational sensor locations used for the modelling presented in this paper are shown on Figure 1. Moisture conditions at each field trial are also measured with a Sentek Diviner $2000^{\circledR}$, a portable water content sensor, to a depth of $1.6 \mathrm{~m}$.

\section{Table 1 Summary of cover material properties}

\begin{tabular}{ccccccc}
\hline \multicolumn{1}{c}{ Material } & \multicolumn{2}{c}{ Grain Size Distribution (\%) } & Porosity & $\begin{array}{c}\text { Specific } \\
\text { Gravity }\end{array}$ & $\begin{array}{c}\text { ksat } \\
\text { (cm/s) }\end{array}$ \\
& Coarse & Sand & Fine & & & \\
\hline Banded-iron formation & 71 & 19 & 10 & 0.28 & 3.14 & $3.5 \times 10^{-4}$ \\
McRae shale & 60 & 20 & 20 & 0.27 & 2.94 & $2.3 \times 10^{-4}$ \\
\hline
\end{tabular}

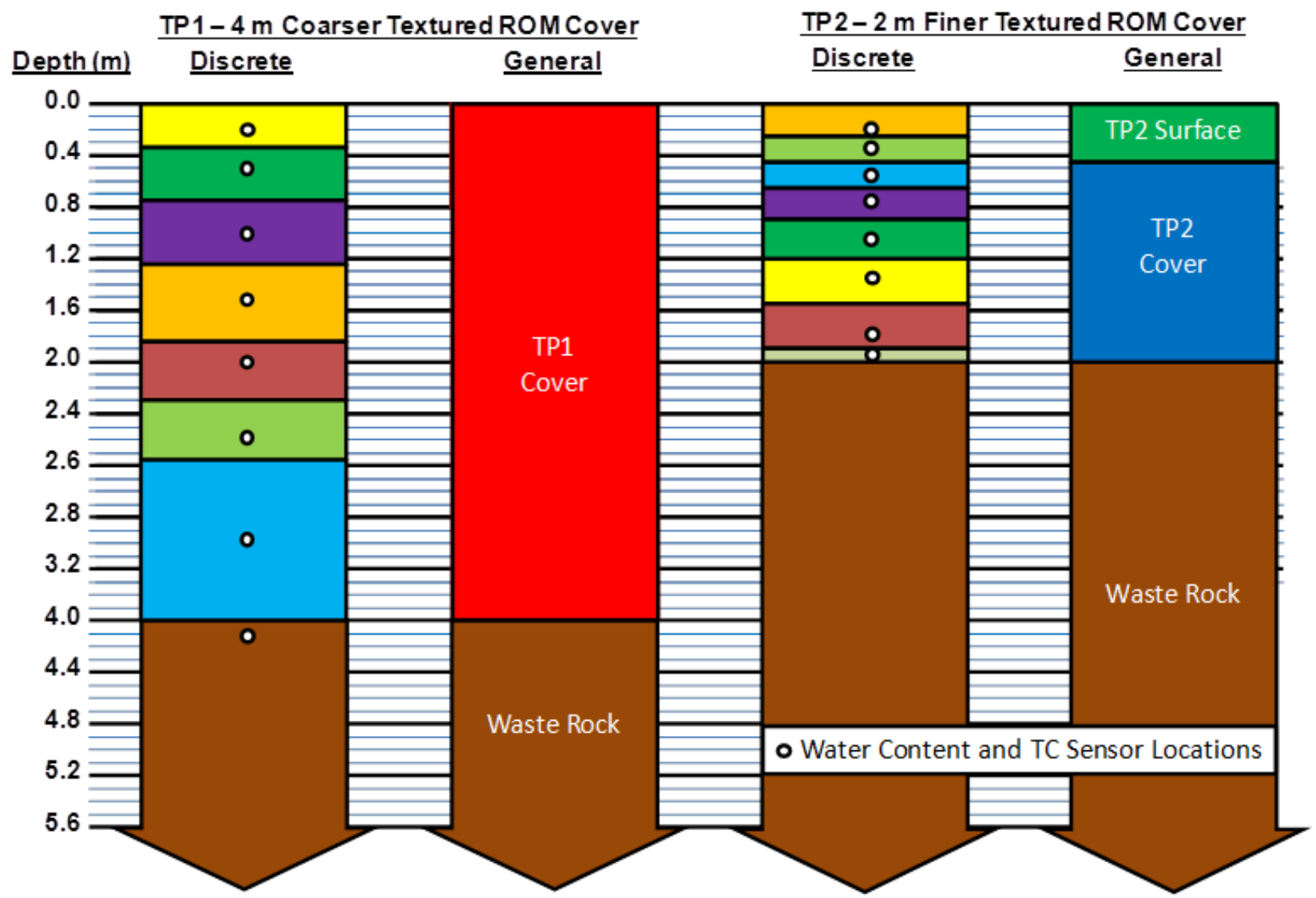

Figure 1 Layering used to simulate the discrete and general field response models for TP1 and TP2. Locations of Sentek EnviroSCAN® capacitance water content and TC sensors also included

An automated Campbell Scientific Inc. (CSI) Model CS700-L tipping bucket rain gauge (with a resolution of $0.2 \mathrm{~mm}$ ) and a CSI NR-Lite were installed at TP2 to monitor rainfall and net radiation, respectively. The remaining climate parameters required for field performance modelling (air temperature, relative humidity, wind speed) are measured at the site's primary meteorological station located approximately two kilometres north of the field trials. Measured climate conditions used for field response models are provided in Figure 2. 

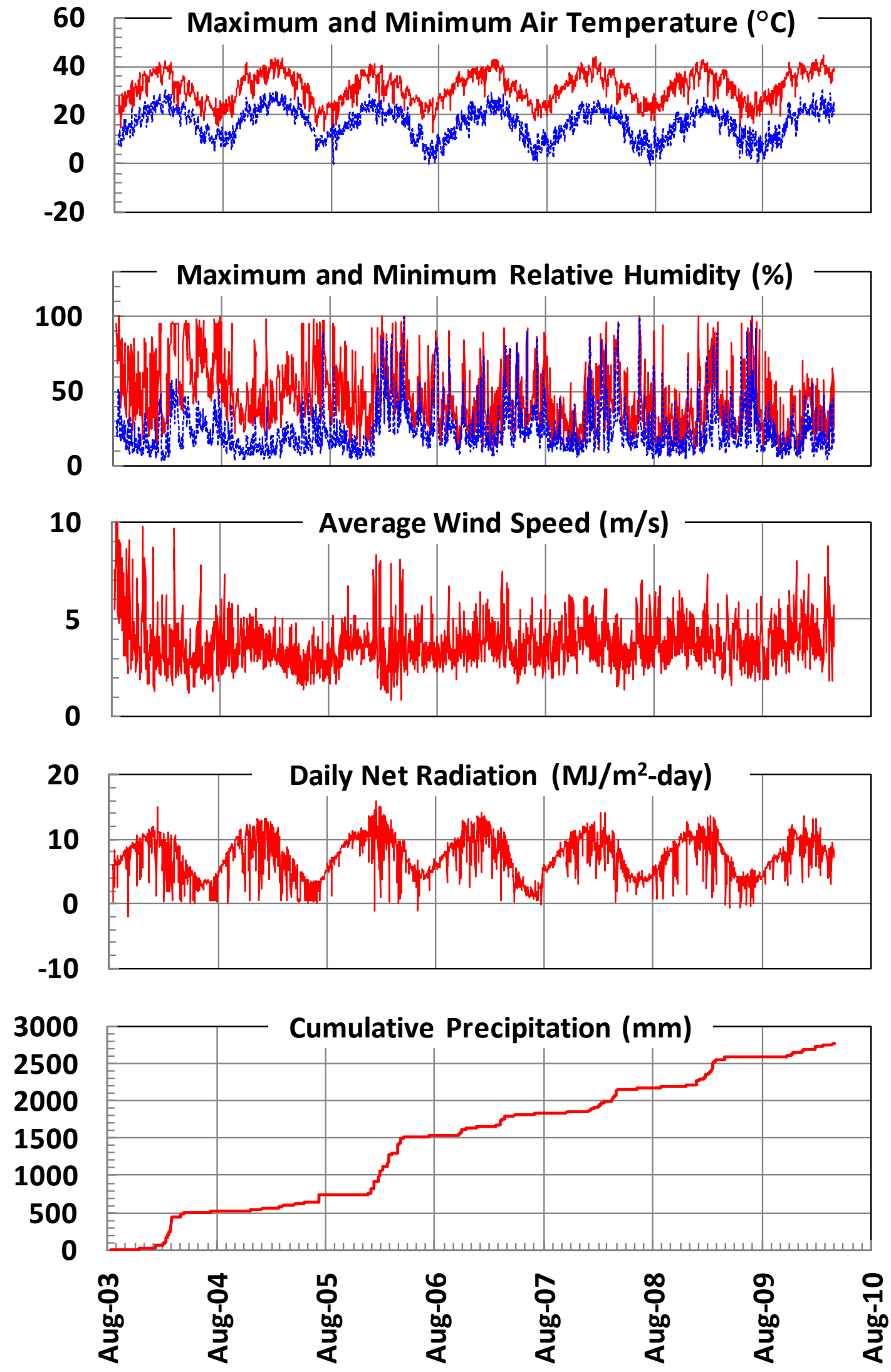

Figure 2 Climate during period of field response simulations 
These installations have been monitored continuously since construction of the field trials. As such, a unique set of cover system monitoring data have developed over the monitoring period as the covers have evolved, as shown in Figures 3 and 4, from bare-surface to vegetated conditions.

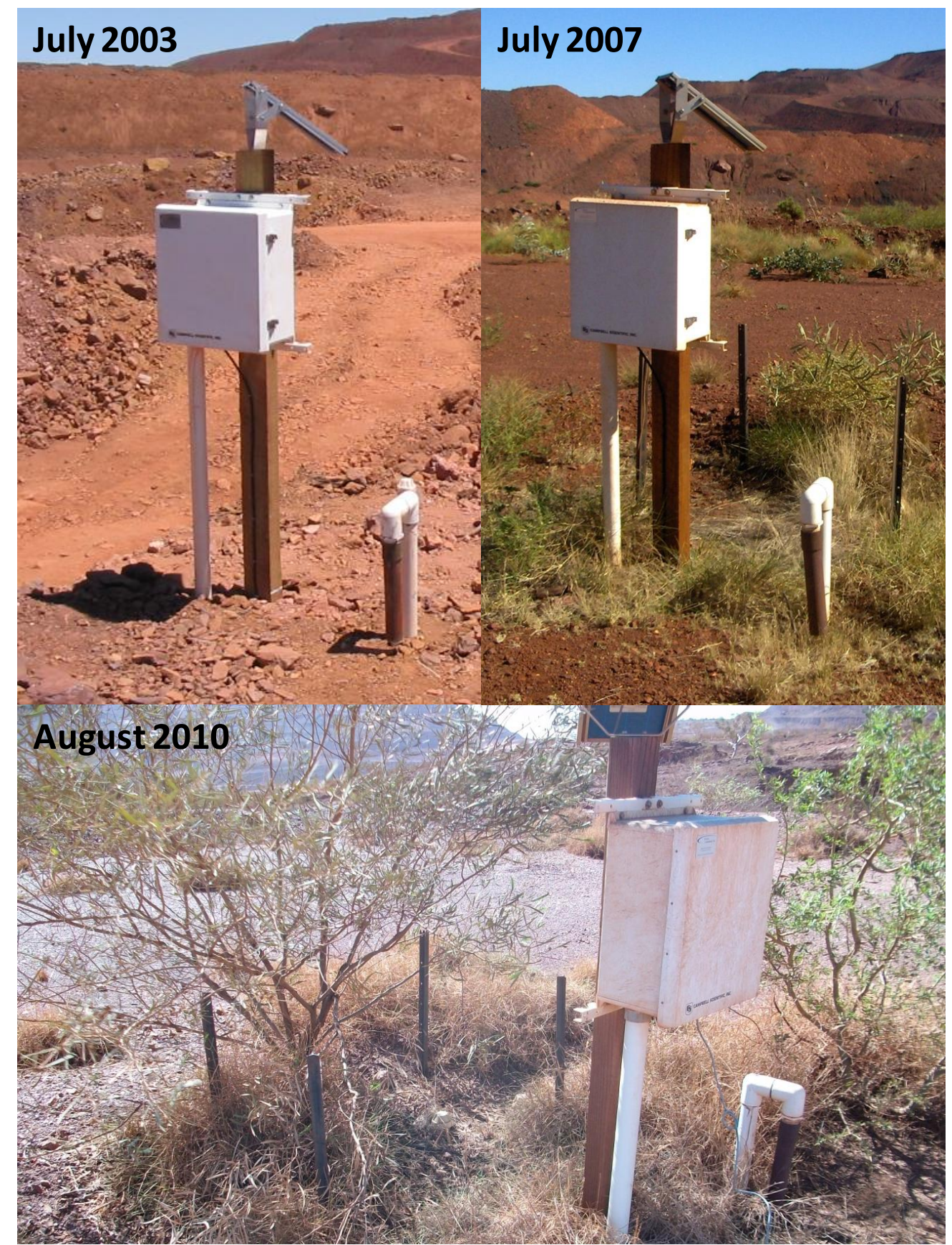

Figure 3 Evolution of TP1 field trial from installation (July 2003) to after period simulated (August 2010) 

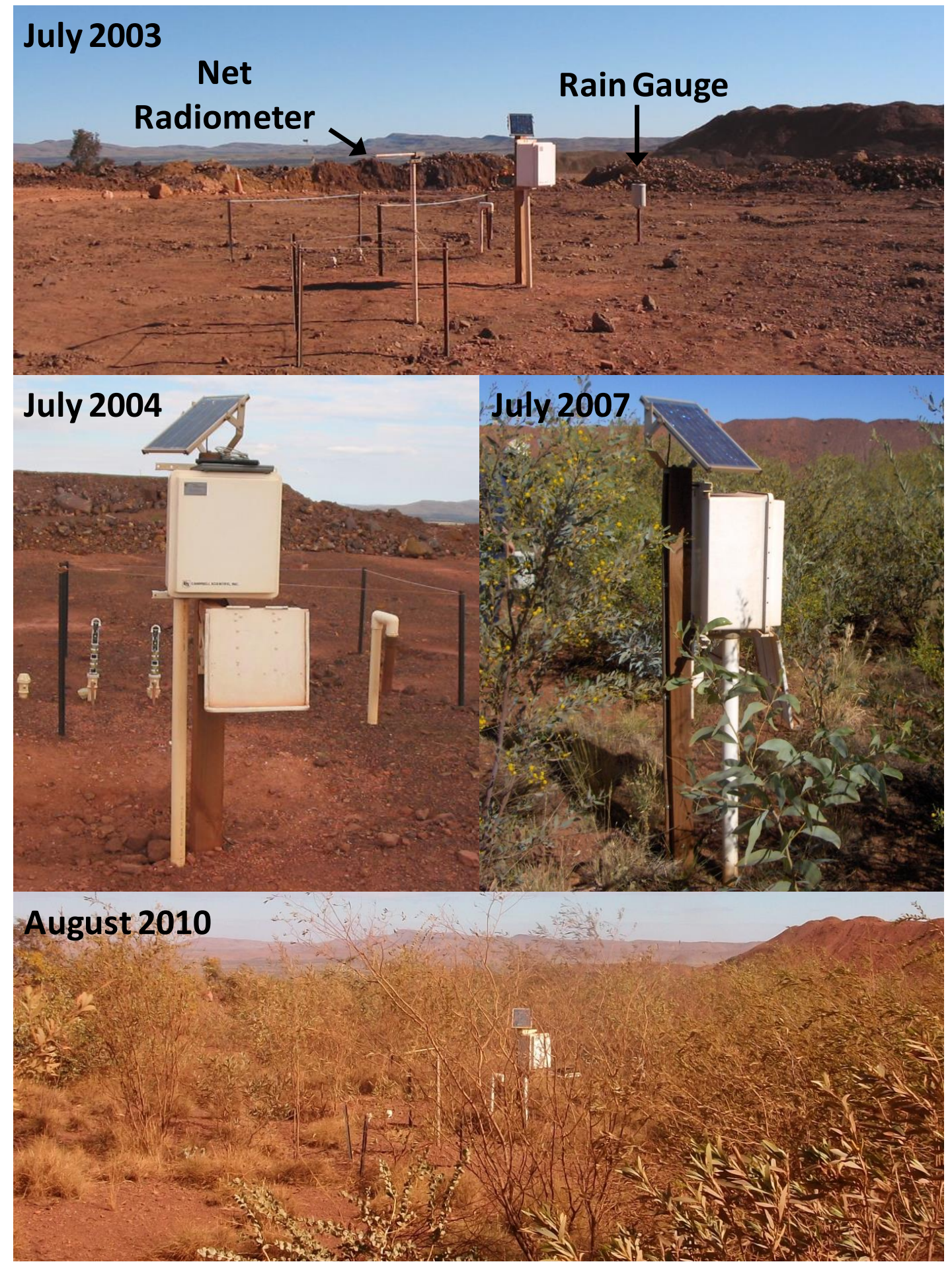

Figure 4 Evolution of TP2 field trial from installation (July 2003) to after period simulated (August 2010). Locations of net radiometer and rain gauge shown

\section{$3 \quad$ Field response models}

Field response models were calibrated using the methods described in Shurniak and O'Kane (2009). Using these methods produced the results for TP1 and TP2 shown in Figures 5 and 6, respectively. The 'discrete' field response models for TP1 and TP2 have coefficient of determination $\left(R^{2}\right)$ values of 0.86 and 0.92 , respectively, for the period of March 2, 2004 to March 31, 2010. March 2, 2004 was chosen as the starting point for comparison as on this date a high rainfall event occurred, which both acclimated the field sensors to installation conditions and gave the model time to overcome any biases inherent in the user-defined 
initial conditions. The results presented in Figures 4 and 5 also show that without vegetation it is impossible for the covers to desiccate as much as the field responses without plants removing stored water from depth.

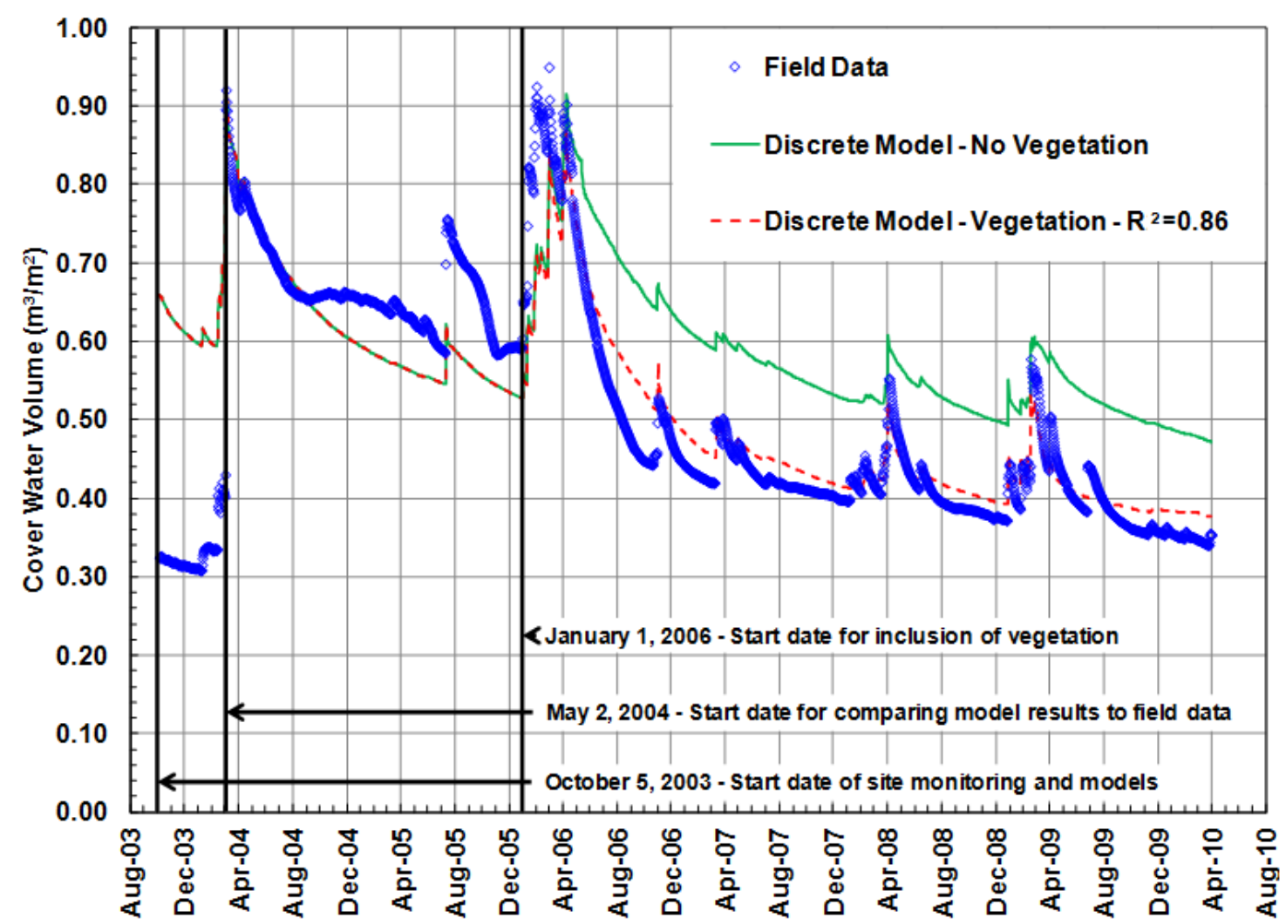

Figure 5 Comparison of TP1 field cover water volumes to results obtained from the TP1 discrete model, with and without vegetation simulated

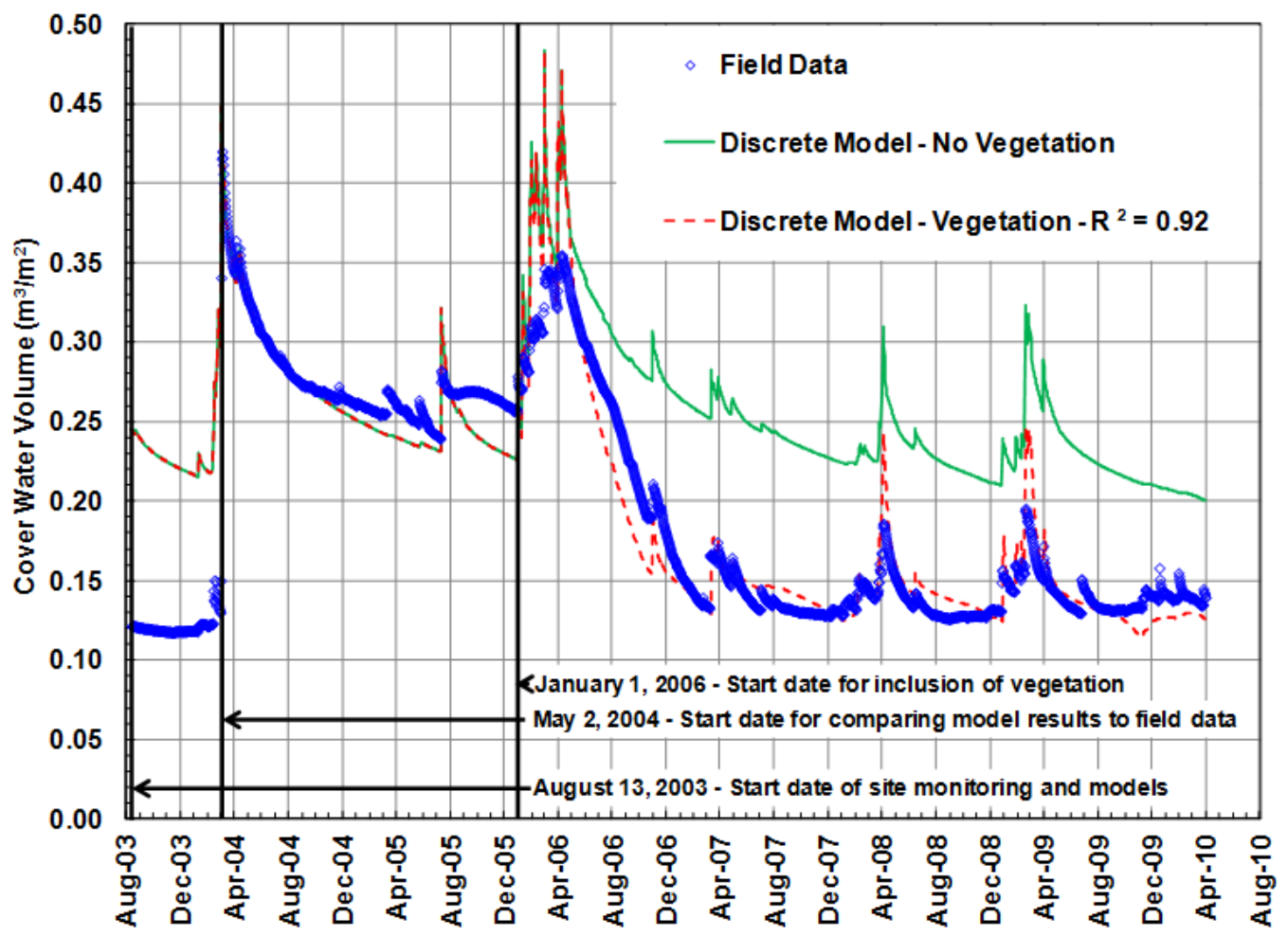

Figure 6 Comparison of TP2 field cover water volumes to results obtained from the TP2 discrete model, with and without vegetation simulated 
A discrete model is developed by calibrating the model using a unique set of material properties for each monitored depth of the soil profile. Once a discrete model is calibrated the estimated material properties for each sensor depth are compared to determine the general layering of the cover system and underlying waste rock. Figure 7 shows the layering for the discrete and general field response models developed for TP1 and TP2. The Figure shows that both discrete models were simulated with eight layers (one for each sensor depth location) but after comparing the calibrated material properties for each layer, it was found that the TP1 cover material could be simulated using one set of general material properties; on the other hand, the TP2 cover material required a surface layer with differing properties from the remaining underlying cover material (Figure 8). TP2 needed a surface layer because the hydraulic properties required to simulate the sensor depths nearer the surface with the discrete model showed a difference in material behaviour from the remainder of the cover profile.

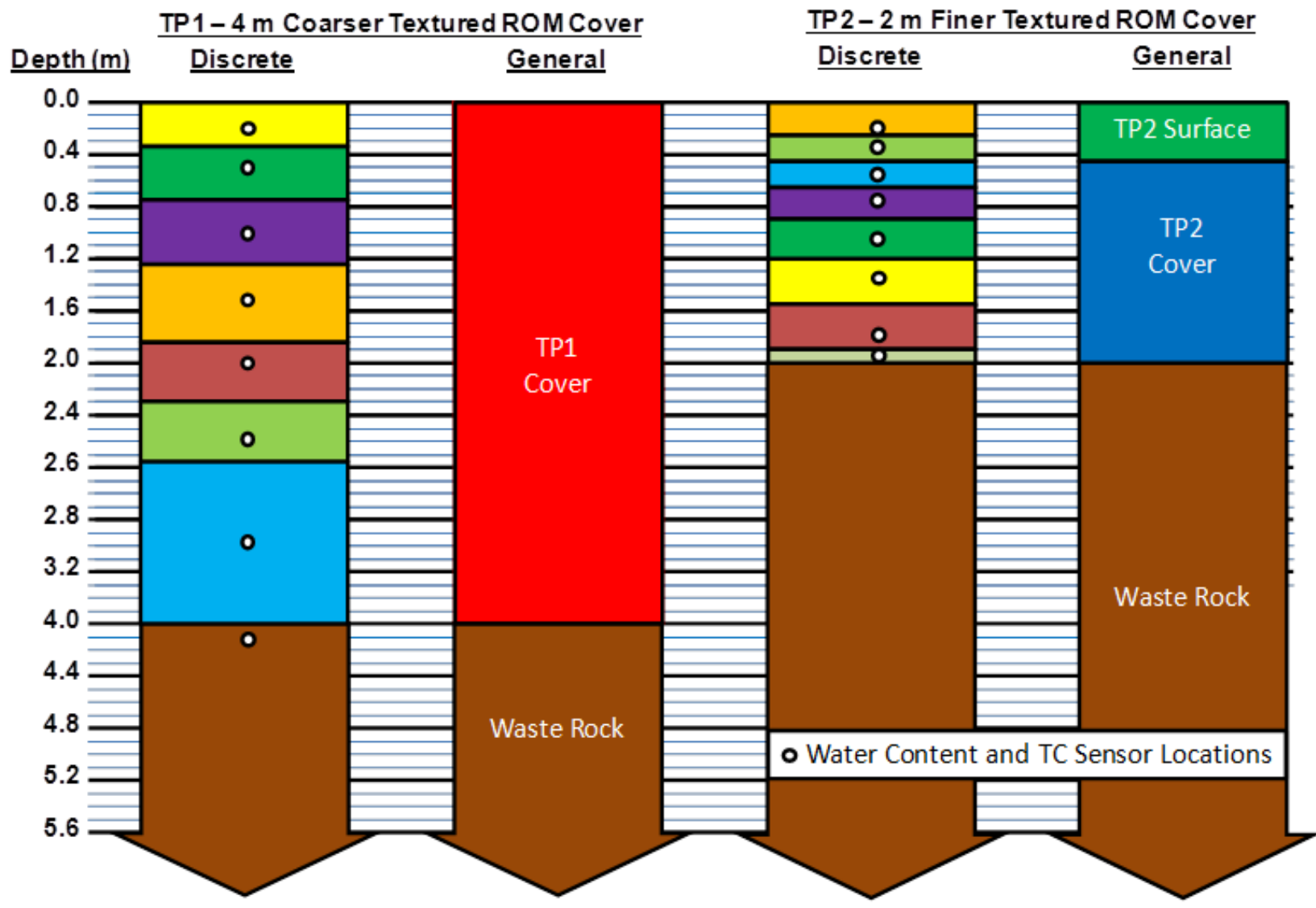

Figure 7 Layering used to simulate the discrete and general field response models for TP1 and TP2. Locations of Sentek EnviroSCAN® capacitance water content and TC sensors also included

The shapes of the hydraulic conductivity functions presented in Figure 8 do not conform to typical unimodal functions. Many materials have heterogeneous pore systems (e.g. cracks, macropores, etc.) that cannot be correctly described with a unimodal curve (Durner, 1994). To this end, Durner (1994) suggested superimposing multiple unimodal curves to define a heterogeneous pore system (described as a multimodal function). Therefore, the functions defined in Figure 8 improve the simulation of both macropore and matrix flow, which increases the accuracy of the model results.

Figures 5 and 6 were compiled by multiplying water content results by the profile volumes they were estimated to represent and adding these water volumes together to come up with an estimate of total cover water volume. Hence, it could be argued that these results may not be as accurate as presented. For example, if there were higher water volumes than measured at surface and lower at depth, the overall result would still look accurate even though the model would not be calibrated. However, as shown in 
Figure 9, the model results presented in this paper are accounting for water movement near surface and at depth.

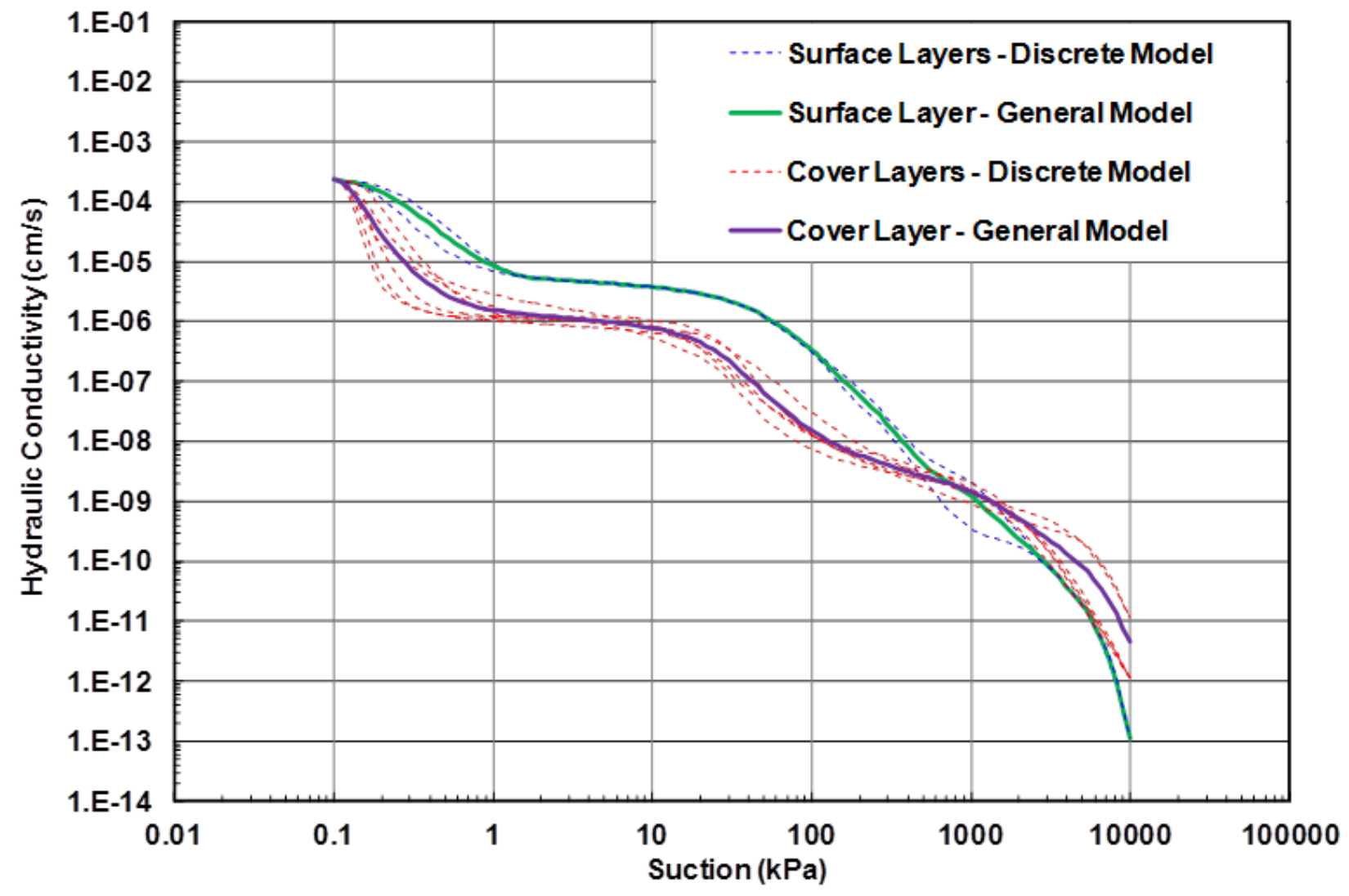

Figure 8 Hydraulic conductivity functions estimated for each la yer of the TP2 discrete and general field response models. Functions show that TP2 can reasonably be simulated with two layers

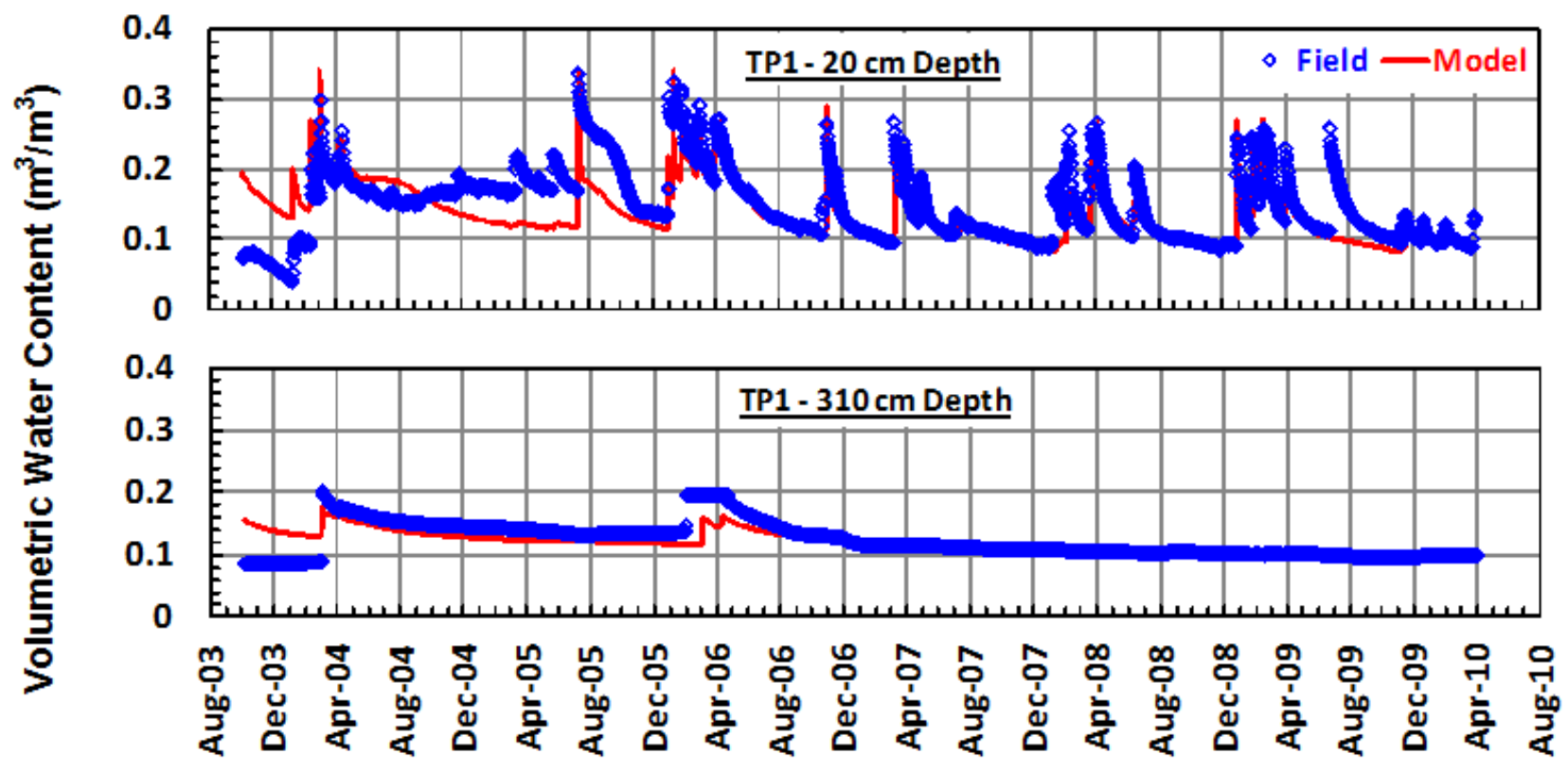

Figure 9 Comparison of TP1 volumetric water content field and model results near surface and at depth 
At this point, no additional changes enhanced model predictions. Hence, the models were considered reasonably calibrated, and their inputs were used as a basis for evaluating long-term cover system performance. However, the model user must be aware that no field response model can be calibrated to perfectly predict all field responses, and that there is no single unique calibration. Different models may lead to equally acceptable representations of field responses; a condition referred to as equifinality (Beven and Binley, 1992; Beven and Freer, 2001; Beven, 2006). Hence, comprehensive testing of the potential range of input parameters (alone and in concert) must be undertaken to determine how sensitive (or insensitive) the model is to changes in each model input. The calibrated model should also be completed and compared to measurements at multiple monitored locations on a cover system to enhance understanding with regards to spatial variations in cover performance. As written by Ebel and Loague (2006):

"...the equifinality problem becomes tractable when both integrated and distributed response data are used to assess model performance."

\section{$4 \quad$ Long-term performance models}

The long-term effect of water passing through a waste rock dump and entering the local ground water system is an important aspect of mine closure planning. Long-term cover performance simulations were completed using the calibrated inputs from the field response modelling to estimate the amount of water passing through the cover systems and entering the waste rock (referred to hereinafter as 'net percolation'). It is important to note that net percolation does not account for the storage potential within the waste rock dump, which would further limit the amount of water reaching the groundwater system.

Both cover systems were simulated for 100 years in succession by applying a 100 year climate database. The historic 100 year climate database developed for the site was estimated from climate data obtained from Wittenoom (2215'S, 11820'E - data from 1950 to 2008, inclusive), Newman (2325'S, 11948'E data from 1972 to 2008, inclusive), and Marble Bar (2110'S, 11945'E - data from 1895 to 2006, inclusive) (BoM, 2012). A day-to-day (or in the case of precipitation, month-to-month) comparison was made between the measurements taken at these site to the measurements taken on site during the field response period. The comparison showed that the measurements of temperature, precipitation, relative humidity, and wind speed at all locations differed in magnitude, but that the patterns corresponded well with each other. Hence, the entire datasets measured at Wittenoom, Newman, and Marble Bar were adjusted to correspond with site measurements. The data obtained from Wittenoom was given precedence as it is the closest site to Tom Price. Any gaps in the 100 year record from Wittenoom were filled with data from Newman or, if data from Newman was also not available, Marble Bar. Net radiation was estimated internally within VADOSE/W. The monthly and yearly average climate conditions estimated for the site based on the generated climate database are summarised in Table 2. The database has maximum, minimum, and average rainfall amounts of $1149 \mathrm{~mm} / \mathrm{yr}, 70 \mathrm{~mm} / \mathrm{yr}$, and $362 \mathrm{~mm} / \mathrm{yr}$, respectively.

The long-term models for both simulations estimated net percolation rates entering the waste rock of less than $5 \%$ of rainfall. This is less than the rates estimated during the field response period of $6 \%$ and $8 \%$ of rainfall for TP1 and TP2, respectively. However, as shown in Figure 10, the field response period is during the wettest period in the historic record. This shows the importance of not basing decisions solely on performance during monitored periods. 
Table 2 Summary of average monthly climate inputs for the historic 100 year climate database estimated for the site

\begin{tabular}{lcccccccc}
\hline Month & \multicolumn{2}{c}{ Temperature $\left({ }^{\circ} \mathrm{C}\right)$} & \multicolumn{2}{c}{ Relative Humidity (\%) } & Wind & \multicolumn{2}{c}{ Rainfall } & Net Rad \\
& Max & Min & Max & Min & (m/s) & (mm) & (\# days) & (MJ/m $\mathbf{m}^{2}$-d $)$ \\
\hline January & 36.4 & 23.9 & 81.6 & 36.3 & 2.24 & 75 & 7 & 12.6 \\
February & 35.4 & 23.4 & 84.5 & 40.9 & 2.20 & 86 & 8 & 11.7 \\
March & 33.1 & 21.4 & 83.2 & 40.4 & 2.19 & 48 & 5 & 9.6 \\
April & 29.5 & 18.1 & 79.2 & 34.4 & 2.23 & 24 & 2 & 7.0 \\
May & 25.5 & 14.0 & 84.1 & 40.0 & 2.24 & 25 & 2 & 5.1 \\
June & 22.1 & 10.3 & 88.8 & 42.4 & 2.24 & 24 & 2 & 4.2 \\
July & 21.2 & 8.7 & 86.5 & 38.5 & 2.21 & 12 & 1 & 4.5 \\
August & 24.7 & 10.8 & 78.9 & 31.0 & 2.28 & 7 & 1 & 6.2 \\
September & 28.7 & 14.1 & 69.5 & 24.1 & 2.19 & 3 & 1 & 8.4 \\
October & 32.0 & 17.5 & 63.8 & 20.8 & 2.21 & 6 & 1 & 10.3 \\
November & 34.5 & 20.5 & 66.3 & 22.6 & 2.22 & 11 & 2 & 11.7 \\
December & 36.1 & 22.8 & 74.0 & 28.8 & 2.29 & 41 & 5 & 12.5 \\
\hline Annual & $\mathbf{2 9 . 9}$ & $\mathbf{1 7 . 1}$ & $\mathbf{7 8 . 3}$ & $\mathbf{3 3 . 3}$ & $\mathbf{2 . 2 3}$ & $\mathbf{3 6 2}$ & $\mathbf{3 7}$ & $\mathbf{8 . 7}$ \\
\hline
\end{tabular}

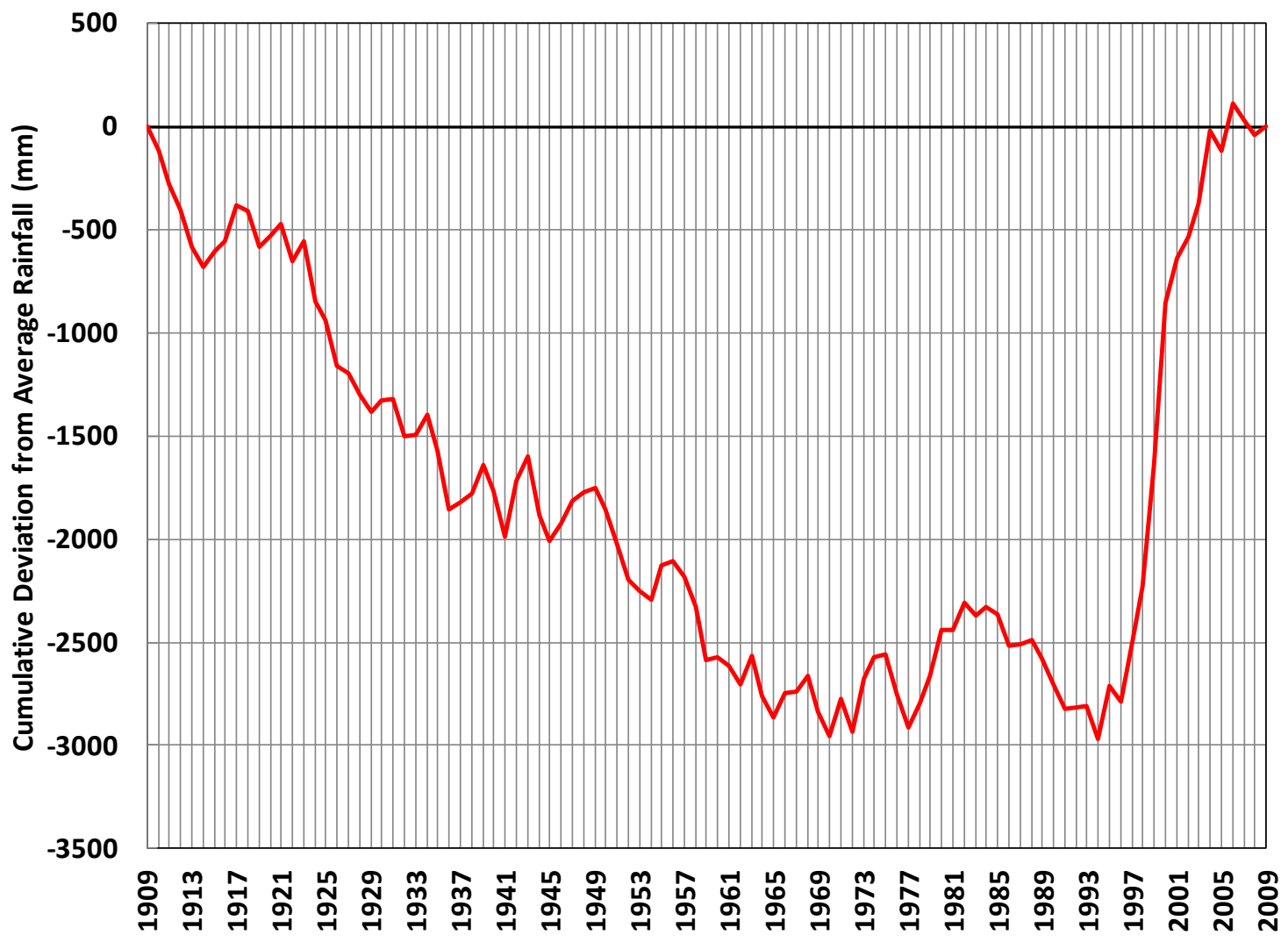

Figure 10 Cumulative deviations from average rainfall for the 100 year historic climate database estimated for the site 
Climate change is a growing concern for estimating future performance of cover systems. Hence, the effects of potential climate change were estimated by adjusting the historic 100 year climate database based on changes predicted by global climate models (GCMs). The GCMs' predictions were obtained from the OzClim website (CSIRO Australia, 2007). The GCMs all predict relatively similar patterns of temperature increase for the site, but vary widely when predicting changes in rainfall amounts. After review of all the potential GCMs provided by the website, the CSIRO Mk3.5 model was chosen as it provided all the climate inputs required by VADOSE/W and predicted the greatest increase in rainfall. The climate model was set to predict future climate based on the worst-case emission and climate sensitivity scenario. The worst-case emission scenario is referred to as ' $\mathrm{A} 1 \mathrm{Fl}$ ', which is characterised by rapid economic growth, a global population that reaches nine billion by 2050 and then gradually declines, the quick spread of new technologies, a convergent world (i.e. income and way of life converge between regions and extensive social and cultural interactions worldwide), and an emphasis on the use of fossil-fuels. The resultant climate change adjusted 100 year climate database has an annual average rainfall of $404 \mathrm{~mm} / \mathrm{yr}, 42 \mathrm{~mm} / \mathrm{yr}$ more than the historic average.

Figure 11 shows a histogram of the annual net percolation rates estimated for the 100 year historic and climate change simulations. The results show that over $60 \%$ of net percolation occurs during the wettest year simulated. Simulating climate change increased net percolation rates by approximately $1 \mathrm{~mm} / \mathrm{yr}$, which resulted in a slight increase in the number of years with net percolation greater than $10 \mathrm{~mm} / \mathrm{yr}$. However, the average net percolation rate for all scenarios remains below $5 \%$ of rainfall.

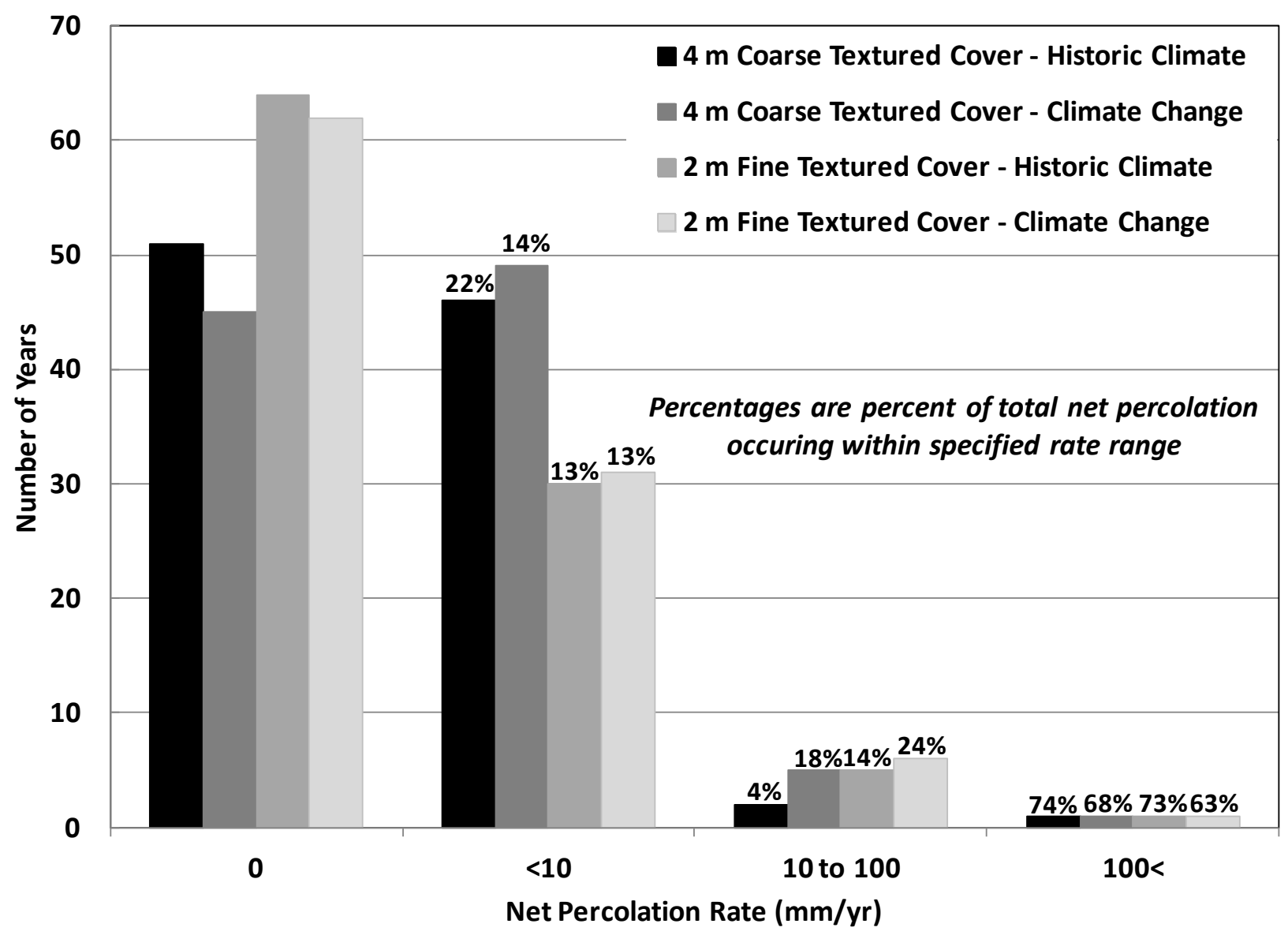

\section{Figure 11 Histogram of annual net percolation rates. Percentages are percent of total net percolation occurring within specified net percolation rate range}

It is important to note that all numerical model have limitations as they are simply mathematical representations of a complex, natural environment. Hence, the following limitations should be noted when interpreting the results from a VADOSE/W model. 
- The conceptual model assumes that movement of water in the unsaturated zone can be represented as Darcian flow in a porous media. The model does not fully account for any potential non-Darcian flow in macropores and/or cracks within the cover system alternatives even with multimodal curves used to define material properties.

- Moisture movement within the cover systems is defined by the unsaturated hydraulic conductivity versus matric suction relationship. This relationship is difficult to measure and consequently is derived by a theoretical algorithm based on the value input for saturated hydraulic conductivity and the moisture retention relationship. The theoretical relationship defines the hydraulic conductivity function over several orders of magnitude, while a single or half order of magnitude change can greatly affect the predicted net percolation results from a simulation.

- Vegetation development is subjectively defined by the model user.

The key advantage to the numerical modelling results summarised herein is the ability to enhance judgement. Hence, rather than a focus on the absolute results predicted, it is recommended that the modelling results be viewed as a tool to understand key processes and characteristics that will influence performance of the cover system, and develop engineering decisions based on this understanding.

\section{Conclusions}

The soil-plant-atmosphere modelling presented in this paper shows that such models are powerful tools that can be used to aid mine closure planning. Calibrated models provide confidence in estimations as they are based on real, field measurements, while the long-term models allow planners to estimate performance during climate periods not measured during mine operations. However, great care and scepticism must be used when developing and evaluating such models as it must be remembered that they are just mathematical representations of the extremely complex, natural environment.

\section{Acknowledgement}

The authors would like to thank RTIO for granting permission to allow this paper to be published.

\section{References}

Beven, K.J. (2006) A manifesto for the equifinality thesis, Journal of Hydrology, Vol. 320, pp. 18-36.

Beven, K.J. and Binley, A.M. (1992) The future of distributed models; model calibration and uncertainty prediction, Hydrological Processes, Vol. 6, pp. 279-298.

Beven, K.J. and Freer, J. (2001) Equifinality, data assimilation, and uncertainty estimation in mechanistic modelling of complex environmental systems, Journal of Hydrology, Vol. 249, pp. 11-29.

BoM (2012) Bureau of Meteorology, climate data online for Wittenoom, Newman and Marble Bar, WA, www.bom.gov.au/climate/data/.

CSIRO Australia (2007) OzClim: Exploring climate change scenarios for Australia, www.csiro.au/ozclim/home.do.

Durner, W. (1994) Hydraulic conductivity estimation for soils with heterogeneous pore structure, Water Resources Research, Vol. 30, No. 2, pp. 211-223.

Ebel, B.A. and Loague, K. (2006) Physics-based hydrologic-response simulation: Seeing through the fog of equifinality, Hydrological Processes, Vol. 20, pp. 2887-2900.

Geo-Slope International Ltd (2009) GeoStudio 2007, Version 7.17, Build 4921, viewed 10 December 2010, http://www.geo-slope.com.

Geo-Slope International Ltd (2010) Vadose zone modelling with VADOSE/W - an engineering methodology, Fourth Edition, GEOSLOPE International Ltd, February.

MEND (2004) Design, construction and performance monitoring of cover systems for waste rock and tailings, Canadian Mine Environment Neutral Drainage Program, Project 2.21.4, July.

RTIO (2012) Rio Tinto Iron Ore, online, www.riotintoironore.com.

Shurniak, R.E. and O'Kane, M. (2009) Methods for simulating measured field responses for long-term performance of mine waste cover systems, in Proceedings Fourth International Conference on Mine Closure (Mine Closure 2009), A.B. Fourie and M. Tibbett (eds), 9-11 September 2009, Perth, Australia, Australian Centre for Geomechanics, Perth, pp. 473-484. 
Simulation of seven years of field performance monitoring at Rio Tinto Iron Ore,

R.E. Shurniak et al.

Mount Tom Price Mine using soil-plant-atmosphere numerical modelling 